Gut, 1974, 15, 614-621

\title{
Incidence and significance of faecal hydroxystearic acid in alimentary disease
}

\author{
H. S. WIGGINS1, JOY R. PEARSON, J. G. WALKER, R. I. RUSSELL, AND \\ T. D. KELLOCK \\ From the Medical Research Council Gastroenterology Unit and Department of Gastroenterology, \\ Central Middlesex Hospital, London
}

SUMMARY Three-day faecal collections were obtained from 87 patients with a variety of gastroenterological diagnoses and 12 control subjects while consuming normal diets. Faecal weight, total fatty acids, and the proportion of hydroxystearic (OHSA) acid were measured. All patients had some easily detectable hydroxystearic acid. It was found that in general the percentage of OHSA in the faecal fatty acids increased with increasing fat output. Thus most patients excreting less than $20 \mathrm{~g}$ of fat per day had less than $5 \%$ OHSA while those with greater steatorrhoea had levels of 6 to $23 \%$. Exceptions were patients with mild steatorrhoea with ileal disease, ileal resections, or small intestinal bacterial colonization, who had more than $5 \%$ OHSA whilst patients with colonic resection had much lower levels of OHSA than otherwise found. It is impossible to determine whether OHSA had a specific cathartic action from this study since the data implicated total fatty acids to the same extent.

The fatty acid composition of faeces in patients with and without steatorrhoea differs from that of the ingested fats (Webb, James, and Kellock, 1963), although when steatorrhoea is gross this effect is less marked. A major factor in determining the differences is bacterial action within the colon (Wiggins, Howell, Kellock, and Stalder, 1969), and one product of this process is hydroxystearic acid (OHSA) which has been identified in the stools in normal subjects and in various disease states (Chipault, 1953; James, Webb, and Kellock, 1961; Rosenfeld and Hellman, 1962; Gompertz and Sammons, 1963). The proportion of OHSA varies in different conditions and it has been proposed that this may be of value in clinical diagnosis (Kim and Spritz, 1968a). Gompertz and Sammons (1963), however, have reported marked variability in the incidence and amount of OHSA in the stools. In order to clarify these points, we have investigated a large representative series including normal subjects.

In addition, because of its chemical structure, it has been suggested that this compound may have a role in the causation of diarrhoea in the malabsorp-

${ }^{1}$ Address for reprint requests: Dr H. S. Wiggins, Medical Research Council Gastroenterology Unit, Central Middlesex Hospital, London, NW10 7NS.

Received for publication 10 April 1974. tion syndrome (James et al, 1961; Hofmann, Poley, Mekhjian, and Phillips, 1970; Soong, Thompson, Poley, and Hess, 1972) and this suggestion has received some recent support. The results of the present study, which are an extension of the original reports from this laboratory (James et al, 1961; Webb et al, 1963), have also been examined from this point of view. A preliminary account of this work has already appeared (Kellock, Pearson, Russell, Walker, and Wiggins, 1969).

\section{Patients and Methods}

\section{PATIENTS}

Patients of both sexes were studied and all were adults.

\section{CHRONIC PANCREATITIS}

Four patients had longstanding steatorrhoea attributed to pancreatic insufficiency. Lundh tests of exocrine pancreatic function were grossly abnormal in all instances, trypsin values being less than $1 \mathrm{iu} / \mathrm{ml}$ with benzoyl arginine ethyl ester as substrate (Cook, Lennard-Jones, Sherif, and Wiggins, 1967). No other cause for steatorrhoea was apparent. None of the patients was receiving treatment with pancreatic enzyme supplements at the time of study; no special dietary measures were in use. 
DIFFUSE SMALL INTESTINAL MUCOSAL DISEASE Sixteen patients had varying degrees of atrophy and inflammation of the small intestinal mucosa on biopsy in association with malabsorption for which no other specific cause could be found. Nine of the patients had classic coeliac disease which responded to withdrawal of gluten from the diet after the present studies were made. Seven other patients had shown no satisfactory response to gluten withdrawal.

\section{ILEAL DISEASE WITH INTACT ILEUM}

Five patients had Crohn's disease of the ileum with classical radiological signs but had not undergone intestinal resection. In two instances the ileal involvement was relatively mild but marked colonic changes were seen on radiographs. Colonic changes had not been detected in the other three cases. A sixth patient suffered from ileal tuberculosis.

\section{ILEAL RESECTIONS}

\section{With recurrent Crohn's disease}

Twelve patients had undergone resection of varying amounts of ileum for Crohn's disease and now showed evidence of recurrence. Subtotal colectomy (sparing the sigmoid colon and/or rectum only) had also been performed in three of these cases.

\section{Without evidence of recurrent intestinal disease}

Five patients had undergone resection (for conditions other than Crohn's disease) of varying lengths of ileum but now showed no evidence of any intrinsic intestinal pathology. Surgery had been performed for a variety of reasons which included foreign body, volvulus, traumatic perforation, posthysterectomy adhesions, and an unexplained stricture.

\section{GASTRECTOMY}

Eleven patients had undergone partial gastrectomy of Polya type for peptic ulcer and were attending hospital for a variety of postgastrectomy problems including recurrent ulceration, dyspepsia, vomiting, and malnutrition.

\section{VAGOTOMY AND PYLOROPLASTY}

(OR OTHER DRAINAGE PROCEDURE)

Seventeen patients were included in this group and were not selected on account of postoperative symptoms.

\section{IRRITABLE BOWEL SYNDROME}

Six patients were believed to be suffering from an irritable bowel syndrome and full investigations for other organic causes of diarrhoea had proved entirely negative.

\section{MISCELLANEOUS CASES}

Sixteen patients with a variety of diagnoses were also studied. The conditions are tabulated with the results in table I together with brief clinical data.

\section{CONTROLS}

Twelve medical students and laboratory personnel acted as a control population. The majority of studies in these subjects were performed during periods of hospital residence when the diet closely resembled that of the inpatients studied.

\section{LABORATORY METHODS}

A three-day faecal inpatient or outpatient collection was made in each subject. When the study was begun no evidence was available about the effect of diet on OHSA excretion and therefore no diets were specified, the patients being encouraged to eat a normal mixture of foods; in the United Kingdom most of the fat eaten is of animal origin. Faecal fat output was measured by the method of van de Kamer, Huinink, and Weyers (1949), except that

\begin{tabular}{|c|c|c|c|c|c|}
\hline \multirow[t]{2}{*}{ Patient } & \multirow[t]{2}{*}{ Sex } & \multirow[t]{2}{*}{ Diagnosis } & \multirow[t]{2}{*}{ OHSA (\%) } & \multicolumn{2}{|l|}{ Faecal Fat } \\
\hline & & & & m-equiv/3 days & g/day \\
\hline $\begin{array}{r}1 \\
2 \\
3 \\
4 \\
5 \\
6 \\
7 \\
8 \\
9 \\
10 \\
11 \\
12 \\
13 \\
14 \\
15 \\
16\end{array}$ & $\begin{array}{l}\mathbf{M} \\
\mathbf{F} \\
\mathbf{F} \\
\mathbf{F} \\
\mathbf{M} \\
\mathbf{F} \\
\mathbf{M} \\
\mathbf{M} \\
\mathbf{F} \\
\mathbf{F} \\
\mathbf{F} \\
\mathbf{F} \\
\mathbf{M} \\
\mathbf{M} \\
\mathbf{F} \\
\mathbf{F}\end{array}$ & $\begin{array}{l}\text { Ileostomy + pancreatic insufficiency } \\
\text { Cirrhosis + hepatoma } \\
\text { Diverticulosis coli } \\
\text { Ileostomy diarrhoea } \\
\text { Large bowel Crohn's disease } \\
\text { Carcinoma pancreas + obstructive jaundice } \\
\text { Hookworm infestation (vegan) } \\
\text { Jejunal resection (for trauma) } \\
\text { Total gastrectomy (for carcinoma) } \\
\text { Folate deficiency of pregnancy } \\
\text { Radiation enteritis } \\
\text { Jejunocolic fistula (after operation) } \\
\text { Peutz-Jegher's syndrome } \\
\text { Resected pancreatic carcinoma (partial gastrectomy) } \\
\text { Stagnant loop (jejunal) following surgery } \\
\text { Primary biliary cirrhosis }\end{array}$ & $\begin{array}{r}2 \\
2 \\
2 \\
2 \\
3 \\
3 \\
3 \\
4 \\
4 \\
7 \\
13 \\
14 \\
16 \\
16 \\
17 \\
17\end{array}$ & $\begin{array}{r}950 \\
46 \\
27 \\
43 \\
26 \\
264 \\
125 \\
75 \\
410 \\
46 \\
935 \\
45 \\
200 \\
960 \\
187 \\
376\end{array}$ & $\begin{array}{r}88.7 \\
4.3 \\
2.4 \\
4.0 \\
2.4 \\
24.6 \\
11.7 \\
7.0 \\
38.3 \\
4.3 \\
87.3 \\
4.2 \\
18.7 \\
89.6 \\
17.5 \\
35.1\end{array}$ \\
\hline
\end{tabular}

Table I Results from unclassified patients 
toluene was substituted for light petroleum in the extraction step since this has been shown to be necessary for the efficient extraction of OHSA (Jover and Gordon, 1962). Small $(2 \mathrm{ml})$ aliquots of the toluene layer were mixed with $5 \mathrm{ml}$ absolute alcohol and titrated with $\mathrm{N}$ sodium hydroxide from a syringe microburette. The rest of the toluene layer was evaporated under vacuum and aliquots of the crude fatty acids were esterified with freshly prepared diazomethane. For gas-liquid chromatography, the methyl esters were dissolved in heptane with warming and injected onto a $5 \mathrm{ft}$ glass column packed with 100-120 mesh diatomite CQ with $3 \%$ SE 30 as liquid phase. The chromatogram was run at $200^{\circ} \mathrm{C}$ in a Pye 104 flame ionization chromatograph. The precision and accuracy of the system was assessed using Applied Science Quantitative Standard Mixture (KA 702-53). A secondary standard mixture containing methyl stearate, 12-hydroxystearate, and palmitate was used as a daily reference. Hydroxystearic acid was identified by its retention time relative to stearic acid. Over a three-year period this ratio was found to be 1.85 (SD \pm 0.01$)$.

\section{SILICIC ACID CHROMATOGRAPHY}

Columns were prepared by slurrying 2.5 g silicic acid (Unisil, Clarkson Chemical Company) in $10 \mathrm{ml}$ portions of heptane and pouring the slurry into glass columns of $1 \mathrm{~cm}$ ID. When all the silicic acid had been added, a further $50 \mathrm{ml}$ of heptane was poured through the column followed by $100 \mathrm{mg}$ crude faecal fatty acids redissolved in $20 \mathrm{ml}$ toluene. The column was eluted with mixtures of diethyl ether and heptane. All unsubstituted fatty acids were eluted with $5 \%$ ether mixtures and hydroxy fatty acids with $30 \%$ ether mixtures. When methyl esters of crude faecal fatty acids were subjected to a similar separation, the fatty acids were eluted with $1 \%$ ether mixtures and the hydroxy fatty acids with $10 \%$ ether mixtures. The mixtures were made up by volume and elution was stepwise.

\section{IDENTITY OF HYDROXYSTEARIC ACID PEAK}

A peak with the same relative retention as 12 hydroxystearic acid (Sigma Chemicals) was found by gas liquid chromatography of the methyl esters and was assumed to be hydroxystearic acid. This was confirmed in 25 cases by silicic acid chromatography of the methyl esters and/or free fatty acids. In no case was a peak with the relative retention of 12hydroxystearic acid found in the non-polar fraction and in all cases at least $85 \%$ of the material in the fraction eluted by the more polar solvent mixture occurred in a single peak with the retention time of hydroxystearic acid. When the weight of the more polar fraction from the silicic acid separation was expressed as a percentage of the total weight recovered, there was a good correlation $(r=0.9)$ between this value and the percentage OHSA determined by the gas-liquid chromatography method (fig 1). Although these findings clearly indicated that we were estimating a monohydroxystearic acid, they gave no indication as to the position of the hydroxyl group. We assumed it to be 10-hydroxystearic acid on the basis of previous workers' results on material isolated independently from different human stools using various methods of structure determination, namely, melting point comparisons (Chipault, 1953), degradation studies (James et al, 1961), and mass spectrometry (Rosenfeld and Hellman, 1962).

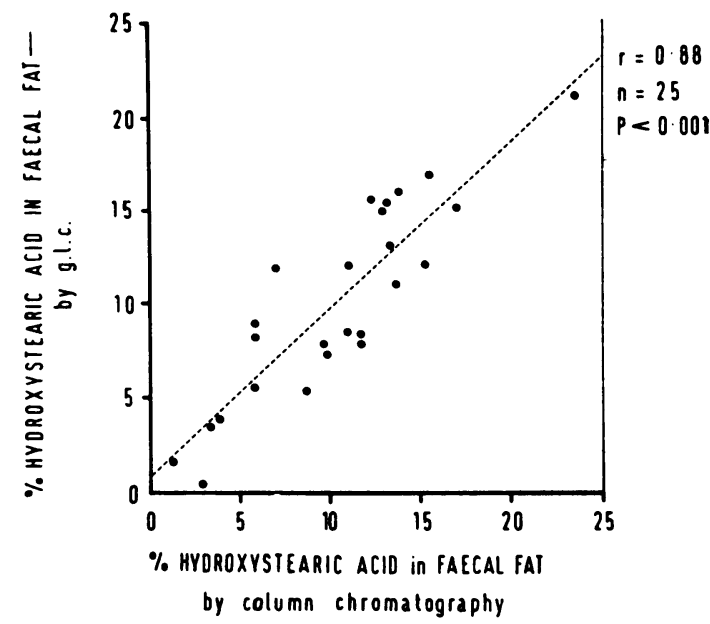

Fig 1 Comparison of values for hydroxystearic acid obtained by different chromatographic techniques.

\section{STATISTICS}

The values quoted for correlation coefficients and coefficients of variation were calculated by standard methods from untransformed data.

\section{Results}

The results of the survey (excluding the miscellaneous patients) are shown in figure 2 where the percentage OHSA is plotted against the three-day faecal fat output expressed in milliequivalents. The use of this method of expressing faecal fat excretion is preferred by us as it is the value actually determined and division of this number by 10 approximates to the fat output in $\mathrm{g} / \mathrm{day}$. Each point represents a single collection and each patient is represented once only. In patients where duplicate determinations of OHSA excretion were carried out, 


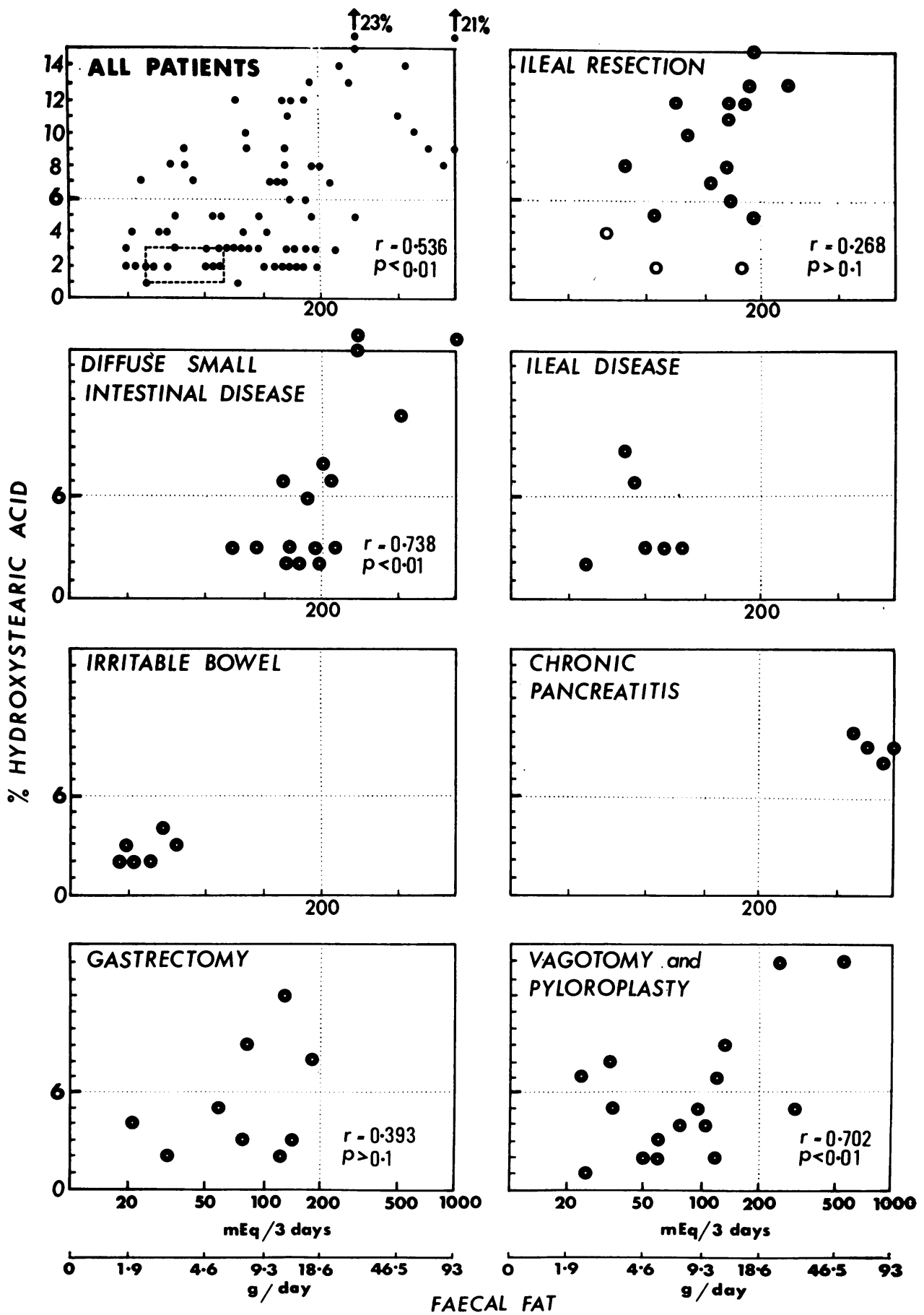

Fig 2 Relationship of hydroxystearic acid to faecal fat output in different groups of patients. The faecal fat output is plotted logarithmically to reduce the congestion of points at the lower fat outputs. The rectangle enclosed by broken lines is the area that the results from the 12 normal subjects occupied. The open circles represent patients with a colectomy. Each point represents the results of a single three-day collection and each patient is represented once only. Correlation coefficients are given for groups where $n>10$. 
results expressed in figure 2 are the first obtained values but when more than two estimations were performed, median results are used.

It is apparent that there is a general tendency for the percentage of OHSA to increase as the faecal fat output rises, and this is true for the majority of groups of patients studied. An exception to this trend occurs with those ileal resection patients (with or without abnormalities of the remaining ileum) who had not undergone colonic resection, where the percentage of OHSA is higher (with respect to total fat excretion) than in the other groups studied. This effect is seen most clearly if the $6 \%$ level of OHSA output and the $200 \mathrm{~m}$-equiv/ 3 days level of faecal fat excretion are used as boundaries. These values enclose $79 \%$ of the subjects with ileal resection and residual colon, but the majority of values in other groups fall outside them. The three ileal resection patients who had also undergone removal of the colon had levels of OHSA comparable to those of the control group. When statistical methods were applied to the groups containing sufficient numbers of cases significant correlations between percentage of OHSA and faecal fat output were found in the patients with diffuse small intestinal involvement and in those who had undergone vagotomy (and drainage) operations. Such correlations were not significant in the patients who had undergone ileal resection but where only a small amount of colon had been removed (vide supra). The correlation was not significant in the group of partial gastrectomy cases, but the majority of these had only minor degrees of steatorrhoea. It was not profitable to apply these statistical methods to the group of cases with chronic pancreatitis because of the small number of patients involved, although they had the percentage of OHSA predictable from the degree of steatorrhoea from which they suffered. Two of the six patients with localized disease of the ileum (but who had not undergoneresection) showed a high percentage of OHSA in the faecal fatty acids similar to that in the resection cases. One of these had isolated ileal Crohn's disease and the other tuberculosis of the terminal small bowel.

In the miscellaneous patients (table I), there was again a correlation between steatorrhoea and OHSA excretion comparable to that found in the classified groups, but with the following exceptions. In patient 1 , one with pancreatic insufficiency and a total colectomy, the OHSA concentration was very low in view of the degree of steatorrhoea, the same was also true of the patient 9 with a total gastrectomy and a patient (no.6) with carcinoma of the pancreas. In two other cases (nos. 12 and 15) there was a disproportionately high percentage of hydroxystearic acid.

\begin{tabular}{|c|c|c|c|c|c|}
\hline \multirow[t]{2}{*}{ Group } & \multirow[t]{2}{*}{ Patient } & \multirow{2}{*}{$\begin{array}{l}\text { Date } \\
\text { (end of collection) }\end{array}$} & \multirow[t]{2}{*}{ OHSA (\%) } & \multicolumn{2}{|l|}{ Faecal Fat } \\
\hline & & & & m-equiv/3 days & g/day \\
\hline \multirow[t]{7}{*}{ Vagotomy and pyloroplasty } & 17 & $\begin{array}{r}\text { 8. } 7.68 \\
\text { 22. } 7.68\end{array}$ & $\begin{array}{l}6 \\
8\end{array}$ & $\begin{array}{l}121 \\
120\end{array}$ & $\begin{array}{l}11.3 \\
11.2\end{array}$ \\
\hline & 18 & 7. 2.69 & 17 & $\begin{array}{l}120 \\
364\end{array}$ & $\begin{array}{l}11 \cdot 2 \\
34 \cdot 0\end{array}$ \\
\hline & & 22. 2.69 & 14 & 555 & 51.8 \\
\hline & & 24. 3.69 & 14 & 620 & 57.9 \\
\hline & & 12. 7.69 & 12 & 138 & $12 \cdot 9$ \\
\hline & 19 & 22. 1.68 & 3 & 89 & $8 \cdot 3$ \\
\hline & & 29. 1.68 & 4 & 80 & 7.5 \\
\hline \multirow[t]{4}{*}{ Gastrectomy } & 20 & 9. 2.68 & 1 & 76 & $7 \cdot 1$ \\
\hline & & 4. 3.68 & 2 & 127 & 11.9 \\
\hline & 21 & 18. 1.68 & 4 & 137 & 12.8 \\
\hline & & 26. 2.68 & 5 & 59 & 5.5 \\
\hline \multirow[t]{9}{*}{ Ileal resection } & 22 & 30. 9.68 & 13 & 48 & 4.5 \\
\hline & & 29.10 .68 & 4 & 25 & $2 \cdot 3$ \\
\hline & & 9. 3.69 & 8 & 46 & $4 \cdot 3$ \\
\hline & 23 & 13. 6.69 & 5 & 186 & $17 \cdot 4$ \\
\hline & & 24. 6.69 & 5 & 150 & 14.0 \\
\hline & 24 & 31.12 .67 & 15 & 186 & $17 \cdot 4$ \\
\hline & & 7.10 .68 & 13 & 105 & 9.8 \\
\hline & 25 & 27. 5.68 & 10 & 85 & 7.9 \\
\hline & & 15.10 .69 & 7 & 180 & $16 \cdot 8$ \\
\hline \multirow[t]{8}{*}{ Diffuse small intestinal disease } & 26 & 19. 5.68 & 15 & 326 & $30 \cdot 4$ \\
\hline & & 27. 5.68 & 11 & 257 & 23.0 \\
\hline & 27 & 15. 1.68 & 3 & 92 & 8.6 \\
\hline & & 5. 2.68 & 3 & 89 & $8 \cdot 3$ \\
\hline & 28 & 29.3 .68 & 21 & 1440 & $134 \cdot 4$ \\
\hline & & 4. 6.68 & 21 & 810 & $75 \cdot 6$ \\
\hline & 29 & 9. 6.68 & 3 & 240 & 22.4 \\
\hline & & 9. 8.68 & 3 & 180 & $16 \cdot 8$ \\
\hline \multirow[t]{2}{*}{ Peutz-Jegher's syndrome } & 13 & 3. 3.69 & 16 & 200 & 18.7 \\
\hline & & 26. 3.69 & 15 & 335 & $31 \cdot 3$ \\
\hline
\end{tabular}

Table II Results of repeated studies on patients without change of treatment 
Both these patients had bacterial colonization of the small intestine (one jejunocolic fistula, one stagnant jejunal loop).

\section{REPRODUCIBILITY OF OHSA EXCRETION}

RESULTS

The reproducibility of OHSA excretion is illustrated in table II where results of several collections from the same patients during periods when there was no apparent change in the subject's condition or treatment are shown. The percentage of fatty acids present as OHSA was reasonably constant for periods varying between one week and 14 months.
The coefficient of variation calculated from these figures was $20 \%$ which was less than that of the faecal fat excretion over the same period $(28 \%)$.

\section{RELATIONSHIP BETWEEN OHSA EXCRETION} AND FAECAL WEIGHT

The correlation between OHSA excretion and faecal weight was examined in two ways. In figure 3 the concentration expressed as milligrams OHSA per gram faecal weight was plotted against total faecal weight: no positive correlation was observed $(r=0 \cdot 12)$. In figure 4, the hydroxystearic acid output in grams per day was plotted against total faecal
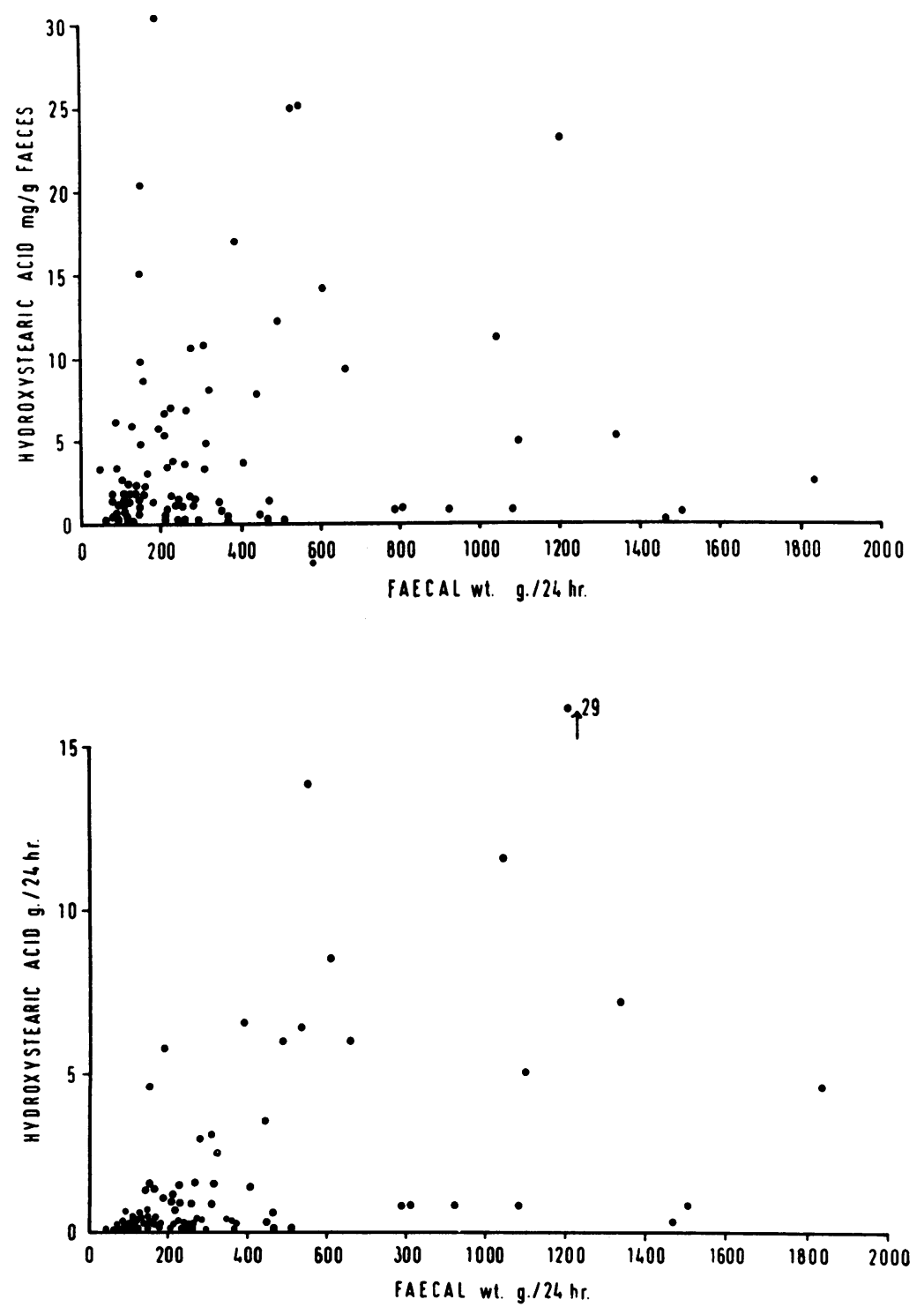

Fig 3 The relationship between the concentration of hydroxystearic acid in the stools and faecal weight.

Fig 4 The relationship between hydroxystearic acid output and faecal weight. 


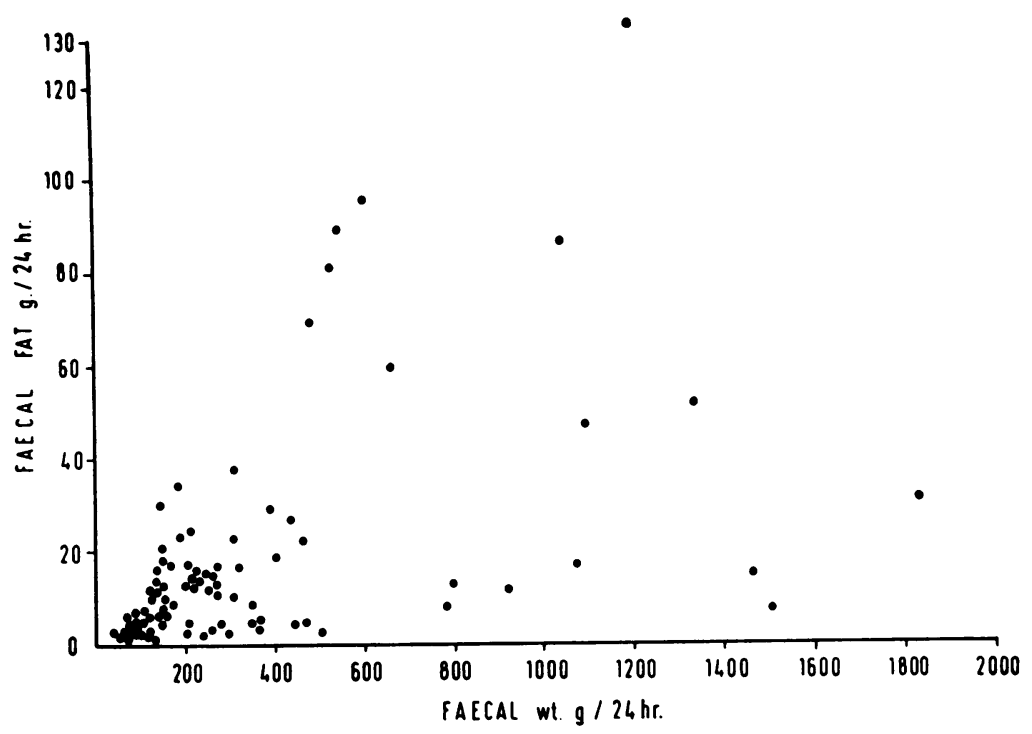

Fig 5 The relationship between total faecal fatty acids and faecal weight. weight: a positive correlation $(\mathrm{r}=0.47, \mathrm{P}<0.001)$ resulted. For comparison, the total faecal fat output was plotted against total faecal weight (fig 5) and a positive correlation was again observed $(r=0.47, P<0.001)$.

\section{Discussion}

It was originally suggested that there might be an association between the presence of hydroxystearic acid in the stools of patients with steatorrhoea and the diarrhoea from which they suffer. This idea, which has recently received support from various quarters (Hofmann et al, 1970; Soong et al, 1972), was prompted by the chemical similarity of the saturated 10-hydroxystearic acid to the unsaturated 12-hydroxyoleic acid, ricinoleic acid, which is the principal constituent of castor oil. However, it has been shown that hydrogenated castor oil in which ricinoleic acid has been converted to 12 -hydroxystearic acid has no specific effect in rats whereas natural castor oil is cathartic (Masri, Goldblatt, De Eds, and Kohler, 1962). If there were a purgative action attributable to OHSA, it could be mediated in several ways. There may be an effect on water absorption or on motility. If the latter were true one might expect a correlation between faecal weight and OHSA expressed as a concentration thereof. Figure 3 shows that this is not the case. Figure 4, however, reveals a positive correlation between faecal weight and OHSA excretion expressed as an absolute value. This suggests that OHSA may have a direct effect on water absorption but the observed correlation of similar magnitude between faecal weight and steatorrhoea makes it impossible to conclude that there is a specific action of hydroxystearic acid. The report of Ammon and Phillips (1972) is compatible with this conclusion.

In our laboratory every faecal sample examined, with the exception of some of those from patients receiving antibiotics, has contained clearly identifiable hydroxystearic acid. In some other reports (Gompertz and Sammons, 1963; Kim and Spritz, 1968a) cases with no hydroxystearic acid have been described. In the study of Gompertz and Sammons (1963) these results may have been due to the choice of the liquid phase (APL) used for their gas-liquid chromatography estimations, for although this was the phase described by James et al (1961), we have found that after an initial period following packing small quantities of the hydroxystearic acid disappeared on this column. Thus samples containing small amounts of OHSA would appear to have none whereas samples with a high proportion of OHSA would be little affected.

It has also been suggested that low or absent values for OHSA excretion in steatorrhoea are peculiar to patients with pancreatic disease (Kim and Spritz, 1968a). This, however, was not the finding in the present series or in other published reports (Gompertz and Sammons, 1963; Bliss and Small, 1970). The explanation for these discrepancies is more difficult to find. It may reside in the nature of the dietary fat consumed by the subjects. Unpub- 
lished observations from our laboratory indicate that the nature of ingested triglyceride can greatly influence the OHSA content of the stool.

One of the aims of the present study was to determine if there were differences in the occurrence of hydroxystearic acid in the faecal fat of different types of patient. Most of the groups showed a similar type of behaviour, with the faecal hydroxystearic acid increasing in proportion to fat excretion. This relationship is only approximate, however, and this is not surprising since the diet was not standardized and three-day faecal collections are liable to some lack of precision. Variation in the timing of collections affects the calculated fat output. The composition of the fatty acids in the diet would also affect the percentage of OHSA formed and the faecal fat output. It was nevertheless found that a positive correlation did exist and this is shown in figure 2. Thus it is clearly necessary to take into account the degree of steatorrhoea when assessing the significance of the OHSA level.

Of paramount interest are the groups of ileal resection patients: these had a disproportionately high level of OHSA in relation to the degree of steatorrhoea. Similar high proportions were also observed in certain patients with severe ileal disease and in the two miscellaneous patients with proven small intestinal bacterial contamination. This latter observation is of interest since Kim and Spritz (1968b) showed that dogs who had surgically constructed blind loops excreted considerably increased amounts of hydroxystearic acid. A common factor in all cases of this type is the simultaneous occurrence of relatively high concentrations of fat, bacteria, and bile salts at a particular site, either in the small intestine as above or in the colon. High levels of OHSA in the ileal resection group are not the sole result of the resections alone since three patients with comparable ileal resections and steatorrhoea but who had undergone removal of most of the colon, thus reducing the time of contact of bile salts, fat, and bacteria, had normal levels of hydroxystearic acid. The main site of formation of OHSA in ileal resection patients is therefore in the colon. This is probably true also in patients with chronic pancreatic insufficiency: in the one patient with this condition who also had an ileostomy, low faecal OHSA excretion was observed in the face of gross steatorrhoea. This is in agreement with results obtained by Bliss and Small (1970) who compared OHSA levels of ileal contents and faeces in pancreatic insufficiency finding low values in the ileum and raised values in the stool.
From the practical point of view, OHSA measurements may have diagnostic implications. The finding of normal (less than $6 \%$ ) levels of OHSA cannot be taken to exclude any diagnosis; however, the finding of more than $5 \%$ OHSA in a patient consuming a normal mixed diet with mild steatorrhoea and without previous surgery would suggest the presence of ileal disease or a stagnant loop syndrome.

We are grateful to many clinicians, especially Sir Francis Avery Jones, for allowing us to study patients under their care. We are also particularly grateful to Mr R. J. Sapsford for many hours of technical assistance.

\section{References}

Ammon, H. V., and Phillips, S. F. (1972). Fatty acids inhibit intestinal water absorption in man: fatty acid diarrhea. (Abstr.) Gastroenterology, 62, 717.

Bliss, C. M., and Small D. M. (1970). A comparison of ileal and fecal lipid in pancreatic steatorrhea. (Abstr.) Gastroenterology, 58, 928.

Chipault, J. R. (1952-3). Studies of fat metabolism in human subjects. Rep. Hormel. Inst. Univ. Minn., pp. 21-26.

Cook, H. B., Lennard-Jones, J. E., Sherif, S. M., and Wiggins, H. S. (1967). The measurement of tryptic activity in intestinal juice as a diagnostic test of pancreatic disease. Gut, 8, 408-414,

Gompertz, S. M., and Sammons, H. G. (1963). The origin of faecal lipids: the composition of faecal fats in human subjects. Clin. chim. Acta, 8, 591-603.

Hofmann, A. F., Poley, J. R., Mekhjian, H. S., and Phillips, S. F. (1970). Hydroxy fatty acid an apparent cause of diarrhea in patients with ileal resection and steatorrhea. (Abstr.). J. clin. Invest., 49, 44a.

James, A. T., Webb, J. P. W., and Kellock, T. D. (1961). The occurrence of unusual fatty acids in faecal lipids from human beings with normal and abnormal fat absorption. Biochem. J., 78, 333-339.

Jover, A., and Gordon, R. S., Jr. (1962). Procedure for quantitative analysis of feces with special reference to fecal fatty acids. $J$. Lab. clin. Med., 59, 878-884.

van de Kamer, J. H., ten Bokkel Huinink H., and Weyers, H. A. (1949). Rapid method for determination of fat in feces. J. biol. Chem., 177, 347-355.

Kellock, T. D. Pearson, J. R., Russell, R. I., Walker, J. G., and Wiggins, H. S. (1969). The incidence and clinical significance of faecal hydroxy fatty acids. (Abstr.). Gut, 10, 1055.

Kim, Y. S., and Spritz, N. (1968a). Hydroxy acid excretion in steatorrhea of pancreatic and non-pancreatic origin. New Engl. J. Med., 279, 1424-1426.

Kim, Y.S., and Spritz, N. (1968b). Metabolism of hydroxy fatty acids in dogs with steatorrhea secondary to experimentally produced intestinal blind loops. J. Lipid Res., 9, 487-491.

Masri, M. S., Goldblatt, L. A., De Eds, F., and Kohler, G. O. (1962). Relation of cathartic activity to structural modifications of ricinoleic acid of castor oil. J. Pharm. Sci., 51, 999-1002.

Rosenfeld, R. S., and Hellman, L. (1962). Excretion of steroid acids in man. Arch. Biochem., 97, 406-410.

Soong, C. S., Thompson, J. B., Poley, J. R., and Hess, D. R. (1972). hydroxy fatty acids in human diarrhea. Gastroenterology, 63, 748-757.

Webb, J. P. W., James, A. T., and Kellock, T. D. (1963). The influence of diet on the quality of faecal fat in patients with and without steatorrhoea. Gut, 4, 37-41.

Wiggins, H. S., Howell, K. E., Kellock, T. D., and Stalder, J. (1969). The origin of faecal fat. Gut, 10, 400-403. 